\title{
Research and Practice of Agricultural Product Quality Traceability Social Intercourse Application
}

\author{
Yang Yong ${ }^{1}$, Wei Tongyang*1,a, Li Min ${ }^{1}$ \\ ${ }^{1}$ Agriculture Information Institute, Chinese Academy of Agriculture sciences.Beijing, China
}

\begin{abstract}
The social intercourse application of agricultural product quality traceability is facing historical opportunities such as the growth of member agriculture, consumption upgrading and grading, rapid development of social media and social services in the current internet era. This research divides the users of social intercourse application of agricultural product quality traceability into producers, consumers and distributors, and points out that the application should have the features of being open and easy to spread, free of charge and easy to access, interesting and attractive, real-time and interactive and for dissemination, it can be carried out through searching and subscribing the producers, recording and forwarding the content, as well as scanning agricultural product traceability QR code. Based on the above-mentioned methods and ideas, the "Nongdu Easy to Trace" Wechat program based on Wechat platform has been developed and has been widely promoted and used in many provinces in China.
\end{abstract}

\section{Introduction}

The quality and safety system of agricultural products in developed countries, like that of China, has experienced a difficult period on its way to the establishment of the relevant laws, standards, specifications and industry recognition[1-4]. As early as 1991, Europe has established the European Organic Regulations, requiring that the files recording the use of fertilizers, pesticides and others be established to all plots to monitor the production process of organic agricultural products. By 2002, beef products to be marketed must meet the standard of being traceable. By 2005, the standard of traceability has been extended to all agricultural products in the EU, and products need to be labeled with traceability labels. In 2002, the United States proposed "From Farm to Table", requiring all enterprises to establish traceability system as soon as possible and to launch traceability action plan for fresh agricultural products. In 2013, the Global Food Traceability Cente was established, focusing on the integration and unification of enterprises, governments, academia, consumers and other fields to jointly promote the cooperation of traceability in the food supply chain. Japan also started to establish and implement the traceability system in the beef production chain as early as 2001. In addition, in developed countries, besides the supervision and implementation of food traceability led by the government, the participatory food security system is also in operation, such as Community Supported Agriculture (CSA), which allows consumers to participate in the producers' agricultural producets production[5]. Many scholars also studied the framework design and platform application of agricultural product traceability system based on big data [6] - [7].
Compared with the major agricultural developed countries, the establishment of traceability system of agricultural products and food in China started late, and even now, it is still in the primary stage. The Food Safety Law was officially implemented on October 1, 2015, which is regarded as "the most strict in history", Article 42 of which stipulates that the state establishes the whole chain traceability system for food safety. Food producers and operators shall establish a food safety traceability system to ensure the food traceability. The State encourages food producers and operators to collect and retain production and operation information by means of information technology and establish a food safety traceability system. In recent years, some the Central Government documents has also been mentioned and required traceability many times. At the National Agriculture Work Conference in 2018, in order to accelerate the quality and safety traceability management of agricultural products, it is required to link the quality and safety traceability of agricultural products with agricultural project arrangement, brand recognition, etc., and bring green food, organic agricultural products and geographically-featured agricultural products into the traceability management. After that, the Ministry of Agriculture and Rural Areas has issued The Opinions of the Ministry of Agriculture and Rural Areas on the Linkage of the Quality and Safety Traceability of Agricultural Products and the Major Agriculture and Rural Areas Establishment, the Promotion of Agricultural Brands, the Certification of Agricultural Products, Agricultural Exhibitions and other work.

In today's Internet era, the interests of relevant agricultural production groups, such as producers, consumers and industrial managers, are increasingly

${ }^{* a}$ Corresponding author: weitongyang@caas.cn 
integrated. And in recent years, the rapid development of social media in the Internet economy has laid an important foundation for the social intercourse application of agricultural product quality traceability and brought unprecedented historical opportunities mainly as follows: (1) the formation and development of member agriculture. In the one-to-one relationship in the member agriculture, in addition to the transfer between agricultural products and funds, the multi-dimensional information transfer and interaction based on consumption trust are becoming increasingly important, in which the social application of traceability provides a vital platform support; (2) consumption upgrading and grading. In terms of agricultural products, when consumers purchase agricultural products, they also can be informed with relevant information like where and how to produce agricultural products and some scientific and entertaining knowledge during the production process, and it could be said that consumption has expanded from agricultural products alone to both material and spiritual consumption of the entire agricultural ecosystem and production and operation community; (3) the growing social media and social services provides more communication and trust links between people. Social media and social services realized undifferentiated information dissemination to different groups of people in a very simple way. Based on this social ecology, the application of traceability is more easily accepted by the public.

\section{Research on Social Intercourse Application of Agricultural Product Quality Traceability}

\subsection{Objects of the Traceability Application}

The objects of the social intercourse application of agricultural product quality traceability can be divided into the following groups: first, producers, who need to demonstrate and prove the safety and quality of their agricultural products and share the relevant process through the traceability platform; second, consumers, who is very important in the traceability, because the ultimate beneficiary of food consumption is consumers, and the traceability for consumers must be the content and form that are easy for them to understand and conform to their browsing habits, and the social traceability meets the needs; finally, the distributors. Although they are not the direct consumers, most of them directly deal with the consumers, and they want to provide their old and new customers with safe and high-quality agricultural products. During the acquisition, besides the origin of products, they also want to know more about the production process for the purpose of both knowing the products themselves and preparing for the publicity and promotion of the products.

\subsection{Characteristics of Traceability Application}

It should have the following characteristics: (1) open and easy to spread. The platform and system of social application must be open, so that all users can directly enter the platform without downloading, and the platform should also be the one which has been widely used by the public; (2) free of charge and no threshold. For most small and medium-sized agricultural producers and operators, traceability is icing on the cake, not like giving a helping hand in the snow, so it will be attractive only when being free of charge and without any threshold, which then can lead to a widespre application; (3) interesting and attractive. The traceability content should take the consumers' perspective, be easy to understand, interesting and attractive, therefore contents like the videos based on social media, ecological environment pictures, stories of new farmers, third-party evaluation given by the society are easier to be accepted and trusted; (4) real-time and interactive. The platform should not be one-way communication and inculcation, but information communication and interaction between producers and consumers. Therefore, consumers should be invited to communicate with and provide feedback to producers for the recorded content.

\subsection{Communication methods of Traceability Application}

Two ways of communication could be adopted: (1) based on the characteristics of social interaction, the overall information registered by producers on the platform can be searched, followed, forwarded and saved by consumers and other users, and producers' interesting record can be easily shared in other relevant social platforms at any time; (2) the traceability QR code of agricultural products itself has the characteristic of communication, and productionoriented users can print and post the QR code in the packaging of agricultural products to let it be scanned and read by interested consumers, and it can even be further spread by sharing on the basis of this dissemination.

\section{Development of Social Intercourse Application Platform of Agricultural Product Quality Traceability}

\subsection{Platform Selection of the Application}

The agricultural product quality traceability platform oriented to social intercourse application should be based on the current widely used social platform, rather than a developed APP system independent of social media. This study choose Wechat Mini Programs as the platform of application, mainly taking into consideration that Wechat Mini Program does not require downloading and installing by users, while it can be found through Wechat homepage, and can be opened directly in Wechat after scanning the QR code in other offline channels or platforms.

\subsection{Functional Design of the Application}

The functions of the platform mainly include the following aspects: first, it displays producers' records of the dynamic ecological moments through a social media, which is convenient for users to click to read, like, 
comment and forward if they are interested; second, based on the concept of member agriculture, the producers can be followed by the consumer users because of their interesting and useful tracebility records, and after following the producers, the users can continuously follow the moments of the production base and have consultation and interaction; third, for new users or users or passers-by who are interested in agricultural products in a certain field, they can search the users of the production base according to the origin and type of agricultural products; fourth, based on the basic registration information and dynamic ecological records of production users, the platform generates traceability $\mathrm{QR}$ code for production users to download, display and print and post during sales of products.

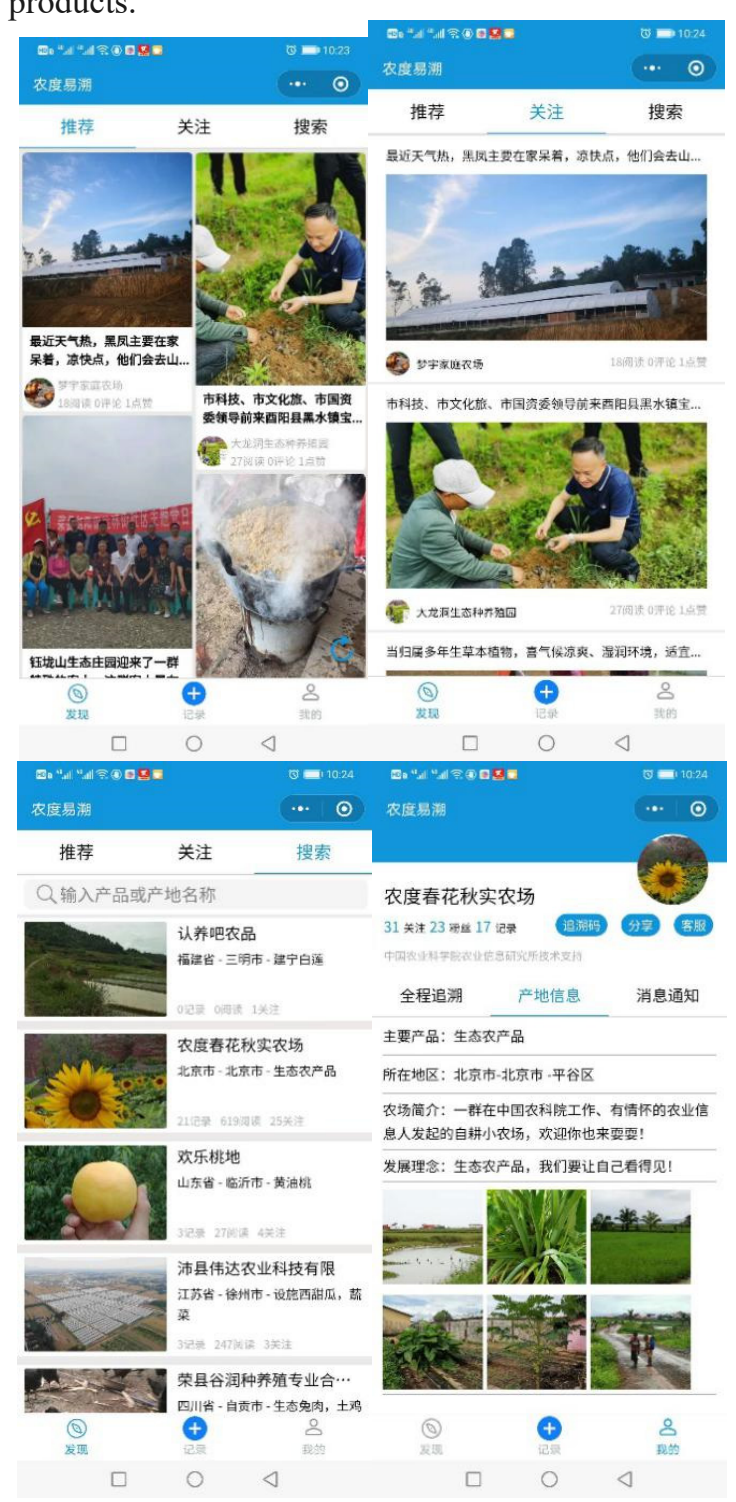

Picture 1-4. System platform interface

\subsection{User Management of the Application}

The users of the system platform are mainly divided into two categories: production users and consumption users. According to the rules of Wechat Mini Program, when users use it for the first time, the system requires users to choose to authenticate or not. Users who do not authenticate are traceless after entering the system. They, only treated as ordinary tourists, cannot follow production users on the platform or comment on users' ecological traceability records. While the users who choose to authenticate can follow and comment. If the users want to further become a production-oriented user, after clicking to make production records, the platform will tell the user to register the user's production base, which requires uploading the farm name, main types of agricultural products, region, contact information, farm profile, development concept and other graphic data and relevant qualifications. After the verification and approval by the platform, the users can start uploading the production record and obtain the traceability QR code of the production base.

\subsection{Content Generation of the Application}

Unlike many traceability systems in the market which mainly focus on the breeding management process during the production process, social traceability puts both producers and consumers in an information sharing and exchange platform. Therefore, the perspective of recording is oriented to adapt to the understanding, interest and concern of consumers. Like most social media platforms, social traceability is to gain consumers' attention through the producers' performance. Therefore, the content mainly reflects the ecological characteristics of the larger environment and the smaller production environment, the producers' attentive production and operation, as well as the third-party evaluation that can be used for demonstration and evaluation, such as being the focus of local governments and scientific research departments, the honors and awards gained, and the recognition of consumers and local peers, etc. Production users can upload records anytime and anywhere, and share them in their Wechat Moments and Wechat groups.

\subsection{Generation of Traceability QR Code of the Application}

The traceability QR code is the core of the quality traceability platform. The quality traceability platform based on the Wechat Mini Programs is mainly a dynamic QR code generated based on the content of the production users. Unlike the traceability QR code of most conventional traceability platforms, the information reflected by scanning is dynamic and users can participate in the interaction and sharing. The two-dimensional code generated in the system can be printed and posted or directly printed on the product package as a part of brand sales for the production and operation entities engaged in the production and sales of agricultural products.

\section{Application of Social Platform of Agricultural Product Quality Traceability}

\subsection{Application and Promotion of the Platform}

Since the "Nongdu Easy to Trace" platform was put into 
operation at the end of 2018, according to the back end statistics, as of May 31, 2020, there have been 136 registered production-oriented users, mainly distributed in Sichuan, Chongqing, Jiangsu, Shanxi, Yunnan, Gansu, Shandong, Qinghai, Heilongjiang and other provinces, many of which have already printed the QR code on the package of agricultural products.

\subsection{Data Analysis of Platform Application}

According to the back end statistics of the platform, the Wechat mini program "Nongdu Easy to Trace" has been used by 2740 users. From the perspective of active users in the past 30 days, the number of male users is significantly higher than that of female users, and the age distribution is mainly 40-49 years old, 30-39 years old and over 50 years old, mainly located in Sichuan, Chongqing, Shanxi, Jiangsu, Beijing and other places.

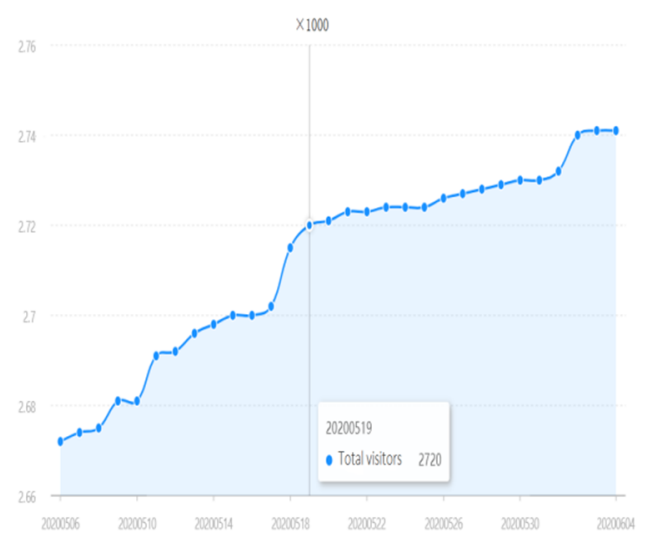

Picture 5. Growth of platform users

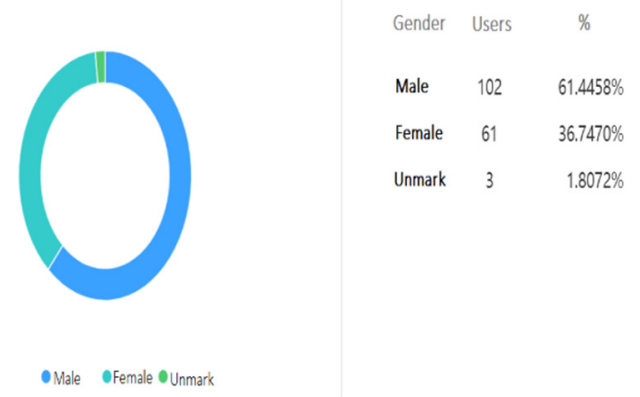

Picture 6. Gender profile of active users in recent 30 days

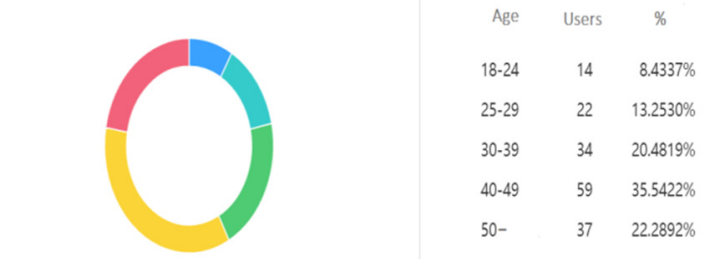

Picture 7 Age profile of active users in recent 30 days

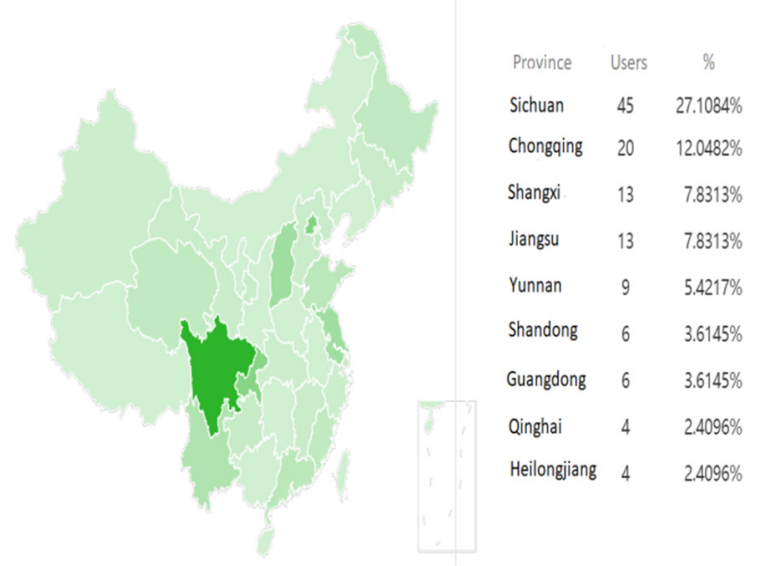

Picture 8. Regional distribution of active users in provinces in the past 30 days

\section{Conclusion}

Based on the results and discussions presented above, the conclusions are obtained as below:

(1) In the current Internet era, the social intercourse application of agricultural product quality traceability is facing historical opportunities, such as the growing member agriculture, consumption upgrading and grading, rapid development of social media and social services.

(2) This research divides the users of social application of agricultural product quality traceability into producers, consumers and distributors, and points out that the application should have the features of being open and easy to spread, free of charge and easy to access, interesting and attractive, real-time and interactive, and for dissemination, it can be carried out through searching and subscribing the producers, recording and forwarding the content, as well as scanning agricultural product traceability QR code.

(3) Based on the above-mentioned methods and ideas, The "Nongdu Easy to Trace" wechat program based on Wechat platform has been developed and has been widely promoted and used in many provinces in China.

\section{Acknowledgments}

This work was financially supported by the Science and Technology Innovation Project of Chinese Academy of Agricultural Sciences (CAAS-ASTIP-2016-AII) and Central Public-interest Scientific Institution Basal Research Fund(No. JBYW-AII-2019-34).

\section{References}

1. Xiu Wenyan,Ren Aisheng. Development and enlightenment of foreign agricultural product quality safety traceability system [J]. Agricultural economics, 2008:206-210(in Chinese).

2. Xing Wenying . American agricultural product safety traceability system $[\mathrm{J}]$. World Agriculture, 2006 , 324( 4):39 41(in Chinese).

3. Zhang Yuxiang. Theory and Practice of agricultural 
Product quality safety traceability system construction . China Agricultural Science and Technology Press, 2008( 8) (in Chinese).

4. Yu Gaoqiang, LI Jiang. Literature review of traceable food research abroad[J]. The financial times2017,664(06):261-263(in Chinese).

5. SHI Yan,Cheng Cunwang,. Harvest Sharing Guidelines for Community Supported Agriculture ( Translated works, Chinese ) , China Renmin University Press:2012.2

6. JIANG Ting. Research on the Framework of Agricultural Product traceability System under the background of big data[J]. Journal of Hefei Normal University, 2015,33(06):51-54(in Chinese).

7. LIU Nian,WANG Feng. Research on the Construction of Agricultural Product Quality safety traceability platform based on big data[J]. 2017,3:104-106(in Chinese). 